\title{
Savings in Medical Expenditures Associated with Reductions in Body Mass Index Among US Adults with Obesity, by Diabetes Status
}

\author{
John Cawley - Chad Meyerhoefer • Adam Biener • \\ Mette Hammer • Neil Wintfeld
}

Published online: 9 November 2014

(C) The Author(s) 2014. This article is published with open access at Springerlink.com

\begin{abstract}
Background The prevalence of obesity has more than doubled in the USA in the past 30 years. Obesity is a significant risk factor for diabetes, cardiovascular disease, and other clinically significant co-morbidities. This paper estimates the medical care cost savings that can be achieved from a given amount of weight loss by people with different starting values of body mass index (BMI), for those with and without diabetes. This information is an important input into analyses of the cost effectiveness of obesity treatments and prevention programs.
\end{abstract}

Electronic supplementary material The online version of this article (doi:10.1007/s40273-014-0230-2) contains supplementary material, which is available to authorized users.

J. Cawley ( $ه)$

Department of Policy Analysis and Management, Cornell

University, 2312 MVR Hall, Ithaca, NY 14853, USA

e-mail: JHC38@cornell.edu

J. Cawley

Department of Economics, Cornell University, 2312 MVR Hall,

Ithaca, NY 14853, USA

C. Meyerhoefer · A. Biener

Department of Economics, Rauch Business Center, Lehigh

University, 621 Taylor St., Bethlehem, PA 18015, USA

e-mail: chm308@lehigh.edu

A. Biener

e-mail: aib210@lehigh.edu

M. Hammer · N. Wintfeld

Novo Nordisk, Inc., 800 Scudders Mill Road,

Plainsboro, NJ 08536, USA

e-mail: mthm@novonoridisk.com

N. Wintfeld

e-mail: nwif@novonoridisk.com
Methods Two-part models of instrumental variables were estimated using data from the Medical Expenditure Panel Survey (MEPS) for 2000-2010. Models were estimated for all adults as well as separately for those with and without diabetes. We calculated the causal impact of changes in BMI on medical care expenditures, cost savings for specific changes in BMI $(5,10,15$, and $20 \%)$ from starting BMI levels ranging from 30 to $45 \mathrm{~kg} / \mathrm{m}^{2}$, as well as the total excess medical care expenditures caused by obesity.

Results In the USA, adult obesity raised annual medical care costs by $\$$ US3,508 per obese individual, for a nationwide total of \$US315.8 billion (year 2010 values). However, the relationship of medical care costs over BMI is $\mathrm{J}$-shaped; costs rise exponentially in the range of class 2 and 3 obesity $(\mathrm{BMI} \geq 35)$. The heavier the obese individual, the greater the reduction in medical care costs associated with a given percent reduction in BMI. Medical care expenditures are higher, and rise more with BMI, among individuals with diabetes than among those without diabetes.

Conclusions The savings from a given percent reduction in BMI are greater the heavier the obese individual, and are greater for those with diabetes than for those without diabetes. The results provide health insurers, employers, government agencies, and health economists with accurate estimates of the change in medical care expenditures resulting from weight loss, which is important information for calculating the cost effectiveness of interventions to prevent and treat obesity. 


\section{Key Points for Decision Makers}

The average inflation-adjusted annual medical care costs of adult obesity in the USA rose from \$US3,070 in 2005 to \$US3,508 in 2010; an increase of $14.3 \%$.

Adult obesity raises US annual medical care costs by \$US315.8 billion (year 2010 values).

Individuals with class 1 obesity ( $30 \leq$ body mass index $[\mathrm{BMI}]<35$ ) do not have elevated healthcare costs, but healthcare costs rise rapidly with BMI in the range of class 2 and class 3 obesity (BMI $\geq 35$ ).

The estimated savings in annual medical care costs from a $5 \%$ reduction in weight is \$US2,137 for those with a starting BMI of 40, \$US528 for those with a starting BMI of 35, and \$US69 for those with a starting BMI of 30 .

The medical care costs for individuals with diabetes are greater than for those without diabetes at every unit of BMI, and, at high levels of BMI, this difference amounts to thousands of dollars per year.

\section{Introduction}

The prevalence of obesity (defined as a body mass index $[\mathrm{BMI}]^{1}$ of $30 \mathrm{~kg} / \mathrm{m}^{2}$ or higher) has more than doubled in the USA in the past 30 years [1]. As of 2011-2012, more than one-third (34.9\%) of adult Americans are obese [2]. This has substantial consequences for the US healthcare system, because obesity is a significant risk factor for type 2 diabetes, stroke, myocardial infarction, cancer, and many other conditions [3-5]. For example, it is estimated that obesity is responsible for up to two-thirds of diabetes and coronary heart disease cases [6].

Obesity-related co-morbidities are complex and multifactorial, and the mechanisms by which obesity contributes to these co-morbidities are not known with certainty. As for some of these mechanisms, research suggests that fat cells secrete leptin, which increases the risk of cardiovascular disease, and resistin, which causes type II diabetes [7]. Other research suggests that the pancreas responds to insulin resistance by increasing secretion of insulin, and that the resulting hyperinsulinemia increases the risk of

\footnotetext{
${ }^{1}$ BMI is equal to weight in kilograms divided by height in meters squared.
}

various cancers [8]. The etiological mechanisms underlying obesity-related co-morbidities (for example, hemodynamic alterations, insulin resistance, hormonal abnormalities, ectopic fat, and secretion of adipokines) continue to be clarified. See Malnick and Knobler [9] for a review of obesity-related co-morbidities and their mechanisms.

The effect of weight and weight loss on medical expenditures is critical information for analyzing the cost effectiveness of interventions to prevent or reduce obesity. Knowledge of this relationship can also offer guidance for targeting interventions to those with the greatest potential savings. Despite the importance of this question, medical care costs at specific levels of BMI are not well established. Four major problems need to be overcome to accurately estimate the relationship between BMI and medical expenditures.

The first problem is omitted variables. BMI is not randomly assigned in the population; people with obesity differ in many ways from those who are not obese (for example, among US women, BMI is negatively correlated with income and education [10]). As a result, a simple correlation of medical expenditures with BMI reflects not only the effect of BMI but also the effect of all the unobserved characteristics that differ between high-BMI and low-BMI individuals.

A second problem that must be addressed is reporting error in weight and height (measurement error). The best data on US medical expenditures comes from the Medical Expenditure Panel Survey (MEPS), but the MEPS contains only self-reports or proxy reports, not measurements, of weight and height. This is problematic, because patterns of misreporting in weight are consistent: people, on average, tend to under-report their weight, with heavier individuals under-reporting more [11]. Reporting error has the potential to bias coefficient estimates, and the direction of the bias can be difficult to determine when the error is correlated with the true value of the variable [12]. Most previous studies of the medical care costs of obesity [13-16] have used the reported values of weight and height without any adjustment for reporting error, and thus their results are likely biased.

The third major challenge is simultaneity, which means a loop of causality between independent and dependent variables. To the extent that medical expenditures affect the characteristic used to model medical expendituresBMI-the impact of BMI on medical expenditures will be incorrectly estimated.

The fourth major challenge is that medical expenditures are a nonlinear function of BMI; for example, they rise exponentially with BMI in the obese range [17]. Thus, accurately estimating medical expenditures at various levels of BMI requires a nonlinear model. 
A previously reported analysis of the impact of BMI on medical expenditures [17] used a well known modeling technique, instrumental variables (IVs), to address the above challenges. The IV method and the criteria to evaluate appropriate use of the technique were comprehensively explained therein, and we refer readers to that work rather than repeating the information here.

This paper offers five contributions to the literature: (1) Use of the IV method to estimate the causal effect of changes in BMI on medical care expenditures. Previous research has only been able to estimate the association, not the causal effect. (2) Use the results of the IV model to provide detailed tables of the estimated medical care expenditure savings given specific reductions in BMI (5, $10,15,20 \%$ ) from specific starting values of BMI $\left(30-45 \mathrm{~kg} / \mathrm{m}^{2}\right)$. (3) We also estimate the IV models and tables of savings by diabetes status. (4) Use of additional data to achieve greater statistical precision. This paper uses MEPS data for 2000-2010 [18], whereas the previous paper estimating the effect of BMI on medical care expenditures with the IV model [17] used data for 2000-2005. (5) We provide estimates for savings in terms of prescription drug costs as well as total medical care expenditures.

\section{Empirical Methods: Two-Part Model of Medical Expenditures}

The distribution of annual medical care expenditures has two important characteristics: it has a mass point at zero (i.e. a substantial fraction of people have zero medical care costs in a given year) and it is right skewed (i.e. a small percentage of individuals have very high medical expenditures). In order to address both of these characteristics, we used two-part models (2PM) (Jones [19]). The first part of the 2PM estimates the probability of having medical expenditures, while the second part estimates the amount of medical expenditures conditional on having any. We specified the first part of the 2PM as a Logit model and the second part as a Gamma generalized linear model (GLM) with a $\log$ link.

Following the suggestion of Manning and Mullahy [20], we used modified Park tests to determine the proper choice of the conditional variance function, the results of which indicated that Gamma GLM is appropriate. HosmerLemeshow tests confirmed that the Gamma GLM is consistent with the data-generating process. ${ }^{2}$ To capture the

\footnotetext{
${ }^{2}$ We also compared the results of the Hosmer-Lemeshow tests with those calculated from an alternative estimation method: ordinary least squares (OLS) of the $\log$ of medical expenditures. For men and women pooled, as well as each gender separately, the Gamma GLM with log link provided the best fit.
}

nonlinearity of medical expenditures over BMI, we included both BMI and BMI squared as regressors.

Given the relationship between obesity and diabetes [21], we estimated models separately by diabetes status. However, when we estimated models separately for people with and without diabetes, we were not able to identify the earlier specification with precision, and instead estimated models that included BMI but not BMI squared. Because the GLM is a nonlinear specification, even the models with just BMI (without BMI squared) were able to reflect (to some extent) the nonlinearity of medical expenditures over BMI. However, they could not capture both the rise in expenditures for people with obesity and the rise in expenditures among those who are underweight (i.e. the full J-shape of expenditures over BMI); to address this, we limited the sample to overweight and obese individuals (i.e. those with $\mathrm{BMI} \geq 25 \mathrm{~kg} / \mathrm{m}^{2}$ ) when estimating models with BMI only (i.e. for people with and without diabetes). For individuals without diabetes, we are able to estimate the 2PM. However, because virtually all of the individuals with diabetes have some medical care expenditures, we estimated a one-part model for that group.

In order to address the reporting error in weight, we estimated IV models. Because the Logit and the Gamma models are both GLMs, we used the GLM IV estimator developed by Carroll et al. [22] and Hardin et al. [23] to estimate the causal effect of BMI on medical expenditures in both parts of the 2PM. Our instruments for respondent BMI and BMI squared were the BMI and BMI squared of the respondent's oldest biological child. ${ }^{3}$ The weight of a biological relative has been used as an instrument for the respondent's weight in previous literature [24-26].

There are two requirements for an instrument in IV. First, it must be powerful. The weight of a biological relative is a powerful predictor of the weight of a respondent because there is a large heritable component to weight; twin studies estimate that $45-75 \%$ of the variation in weight across people is genetic $[27,28]$. As expected, our instruments had significant power in the first stage of the IV models, with an $F$ statistic of 581 for the full sample, which far exceeds the minimum standard for instrument power of $F=10$ [29].

The second requirement for an instrument is validity: the instrument must be uncorrelated with the error term in the second stage. In the present context, this means that the weight of the biological child must be uncorrelated with the respondent's medical care costs after controlling for predicted respondent weight and other observed characteristics. Validity would be threatened if both the respondent

\footnotetext{
3 We obtained similar results using the BMIs of higher-parity biological children, but there was a higher response rate to questions about height and weight for older children and thus we maximized statistical power by using the eldest.
} 
and the biological child are affected by a common household environment that is also directly correlated with the respondent's medical expenditures. However, a large literature in behavioral genetics finds no detectable effect of a shared household environment on weight. For example, a comprehensive review concluded that "[E]xperiences that are shared among family members appear largely irrelevant in determining individual differences in weight and obesity" [30], and, more recently, Wardle et al. [31] concluded, "Contrary to widespread assumptions about the influence of the family environment, living in the same home in childhood appears to confer little similarity in adult BMI beyond that expected from the degree of genetic resemblance." One must always be cautious with regard to the validity of instruments, which is ultimately untestable; however, given the consistent finding that similarity in weight between biological relatives is attributable to genetics, we believe there is enough suggestive evidence regarding power and validity to proceed with the use of weight of a biological relative as an instrument for respondent weight.

Due to the nonlinearity of the relationship between BMI and medical spending, the impact on medical expenditures of a given change in BMI may be different at every starting BMI level. In order to accurately characterize the impact of changes in BMI across the distribution of obese individuals, we computed the marginal impact of $5,10,15$, and $20 \%$ reductions in BMI on medical expenditures from starting BMI values ranging from 30 to $45 \mathrm{~kg} / \mathrm{m}^{2}$.

All of our models control for the following regressors: sex, race/ethnicity (white, black, Hispanic, other race), respondent age (20-34, 35-44, 45-54, or 55-64 years), education level (no high school diploma, high school graduate, some college, bachelor's degree or higher), Census region (Northeast, Midwest, South, West), whether the respondent lives in a metropolitan statistical area (MSA), whether the respondent is married, household composition (number of household members aged $0-5$ years, $6-17,18-64$, and 65 or older), whether the survey information was self-reported as opposed to proxy reported, indicator variables for year, the gender of the child whose weight serves as the instrument, and the age in months of the child whose weight serves as the instrument.

In a supplementary analysis, we calculated the excess medical care costs caused by obesity, both per obese individual and for the USA as a whole. These estimates

\footnotetext{
${ }^{4}$ We do not report potential savings associated with weight loss starting from BMI above $45 \mathrm{~kg} / \mathrm{m}^{2}$ because the number of respondents in the sample who have BMI in that range is so small that marginal effects are imprecisely estimated. In particular, these individuals represent less than $2 \%$ of the pooled sample of men and women with BMI $<80 \mathrm{~kg} / \mathrm{m}^{2}$ and biological children between the ages of 11 and 20 .
}

were based on IV models in which the endogenous regressor is an indicator variable for obesity (BMI $\geq 30 \mathrm{~kg}$ / $\mathrm{m}^{2}$ ), and the instruments continue to be the BMI and BMI squared of the respondent's oldest child. ${ }^{5}$

\section{Data: Medical Expenditure Panel Survey}

We use data from the 2000-2010 waves of the MEPS, which is a comprehensive, nationally representative survey of the US civilian non-institutionalized population conducted annually since 1996 using an overlapping panel design (Davis [32]). Respondents are surveyed about their medical care use and expenditures over the course of 2 years through five interview rounds. In addition, utilization and expenditure data are collected directly from participants' medical service providers and pharmacies through the Medical Provider Component. Thus, the MEPS contains the richest and most complete data on medical care utilization and expenditures for a nationally representative sample of Americans.

We limited the sample to adults between the ages of 24 and 64 years with biological children between the ages of 11 years (132 months) and 20 years (240 months). ${ }^{6}$ Pregnant women were dropped from the sample. ${ }^{7}$ Those with BMI above $80 \mathrm{~kg} / \mathrm{m}^{2}$ were also dropped $(N=140$ over 10 years of data) because their medical expenditures could not be precisely estimated using our models. We used the relationship mappings available in the restricted-use version of the MEPS data to identify the biological children, stepchildren, and foster children of the respondent and thus ensure that only biological children were used as instruments. We did not use information on children younger than 11 years because rates of non-response for their weight and height are high. The weight and height of each individual in the household was typically reported by a single respondent, most often the wife/mother. We excluded two individuals with extremely high reported medical

\footnotetext{
5 This approach uses a linear regression in the first stage, which is most appropriate when the endogenous and mis-measured regressor is continuous. While it is not uncommon to estimate IV models with a linear first stage when the endogenous regressor is discrete, the resulting coefficient estimate may be biased. Black et al. [33] show that if the discrete endogenous variable suffers only from nonclassical measurement error, then the true value of the coefficient will generally lie between the OLS and IV estimates in the case of univariate regression. Frazis and Loewenstein [34] show that if the variable is both endogeneous and mismeasured, then the true value of the coefficient lies within bounds applied to the IV estimate.

${ }^{6}$ Specifically, we limited the sample to adults aged 20 and over, but the youngest adult with a child of at least 11 years of age is 24 , so 24 is the minimum age of a respondent in our estimation sample.

7 We dropped 643 women with MEPS clinical classification codes from 177 to 196, indicating that they had a normal pregnancy or delivery, abortion, or pregnancy complication during the year.
} 
expenditures (in excess of \$US506,000 in the past year). The size of our IV sample for all adults pooled was 41,435. When we divided the sample by glycemic status, and dropped those with BMI $<25 \mathrm{~kg} / \mathrm{m}^{2}$, we had 26,707 individuals without diabetes and 2,308 individuals with diabetes.

We aggregated medical expenditures over all types of care, including inpatient, outpatient, prescription drugs, and other care (which includes dental, vision, home healthcare services, and medical equipment, but excludes spending on over-the-counter medications). We also present results separately for prescription drug expenditures. In many cases, models for other categories of expenditures could not be precisely estimated. To ensure comparability over time, medical expenditures in each year were converted to year 2010 dollars using the Consumer Price Index of the US Bureau of Labor Statistics [35].

The MEPS asks whether each respondent has ever been diagnosed with certain 'priority' conditions of interest, including diabetes. ${ }^{8}$ A limitation of the MEPS is that it does not use International Classification of Diseases, ninth edition (ICD-9) codes for diagnosis and does not conduct any objective test for diabetes (e.g. fasting plasma glucose); thus there is an unknown degree of misclassification bias (e.g. from undiagnosed cases or incorrect recall).

The medical care cost savings associated with a given reduction in $\mathrm{BMI}(5,10,15$, or $20 \%)$ from a given starting value of BMI (each unit from $30 \mathrm{~kg} / \mathrm{m}^{2}$ through $45 \mathrm{~kg} / \mathrm{m}^{2}$ ) were calculated as follows. The model was estimated for the relevant sample, and the predicted value of medical expenditures was calculated for each individual by multiplying the predicted value in the first part of the $2 \mathrm{PM}$ (i.e. the individual's predicted probability of incurring any medical expenditures) by the individual's predicted value in the second part of the 2PM (i.e. the individual's predicted medical expenditures if the respondent was to incur any). For each individual, medical expenditures were predicted for both the starting value of BMI and the reduced value of BMI, after which we calculated the average across all individuals of the change in predicted medical expenditures that is associated with a reduction from the higher BMI to the lower BMI, weighted using the MEPS survey weights.

MEPS data were collected through a stratified multistage probability design, which we accounted for in the calculation of the standard errors of these marginal effects. Specifically, we used the method of balanced repeated replications to estimate standard errors, accounting for

\footnotetext{
8 The exact wording of the question in the MEPS priority conditions codebook is: " $\{$ Other than during pregnancy, (have/has)/(Have/Has) $\}$ (PERSON) ever been told by a doctor or other health professional that (PERSON) had diabetes or sugar diabetes?".
}

clustering at the primary sampling unit level, stratification, and weighting [36].

\section{Empirical Results}

\subsection{Summary Statistics}

Summary statistics for the estimation sample are listed in Supplementary Online Appendix Table A. For the sample as a whole, $84 \%$ of respondents incur some medical care costs, and the average annual expenditures among those who incur any is \$US3,372 (year 2010 values). The average BMI in the sample, which is based on self-reported values, is $28.1 \mathrm{~kg} / \mathrm{m}^{2}$.

\subsection{The Impact of Body Mass Index (BMI) on Medical Expenditures}

Figure 1 describes the relationship between BMI and total annual medical care expenditures estimated by the IV model for all respondents utilizing MEPS 2000-2010 data (year 2010 values). ${ }^{9}$ For values of BMI with many observations (the dotted line is high), the estimates will be more precise, with tighter confidence intervals (i.e. the dashed lines will be closer together). Figure 1 can be compared with the previously reported estimates based on 2000-2005 data in figure 1 of Cawley and Meyerhoefer [17]; the introduction of additional data does not affect the estimated relationship between BMI and medical care expenditures. Expenditures continue to have a J-shape over the BMI range; i.e. expenditures fall with BMI through the underweight and healthy weight categories, are relatively constant with BMI in the overweight category, then rise exponentially with BMI through the obese category, especially at BMI levels $>35 \mathrm{~kg} / \mathrm{m}^{2}$. The BMI value associated with minimum expenditures continues to be roughly $25 \mathrm{~kg} / \mathrm{m}^{2}$, the threshold for overweight. The implications of the nonlinearity are important; for example, it implies that, in the obese range, savings from a given reduction in weight will increase with the starting BMI.

Table 1 presents results for all adults pooled; each table cell lists the reduction in annual medical care costs associated with a given percent reduction in $\operatorname{BMI}(5,10,15$, or $20 \%)$, from a given starting BMI (each unit between $30-45 \mathrm{~kg} / \mathrm{m}^{2}$ ). Below that is listed the standard error in parentheses; savings that are statistically significant at the $5 \%$ level are listed in bold. These estimates are based on the IV model.

\footnotetext{
${ }^{9}$ Each of the lines in Fig. 1 is a smoothed curve that is fit through 14 data points plotted for BMI values ranging from 17.5 to $50 \mathrm{~kg} / \mathrm{m}^{2}$, at intervals of $2.5 \mathrm{BMI}$ points.
} 
Fig. 1 Predicted total annual medical expenditures from the instrumental variables model. Data: Medical Expenditure Panel Survey (MEPS) 2000-2010 [18]. Expenditures are in \$US, year 2010 values. Dashed lines represent $95 \%$ confidence intervals, which have been adjusted for the complex design of the MEPS. Medical expenditures are denoted by the solid line and are measured on the left axis. The dotted line indicates the distribution of individuals in the population

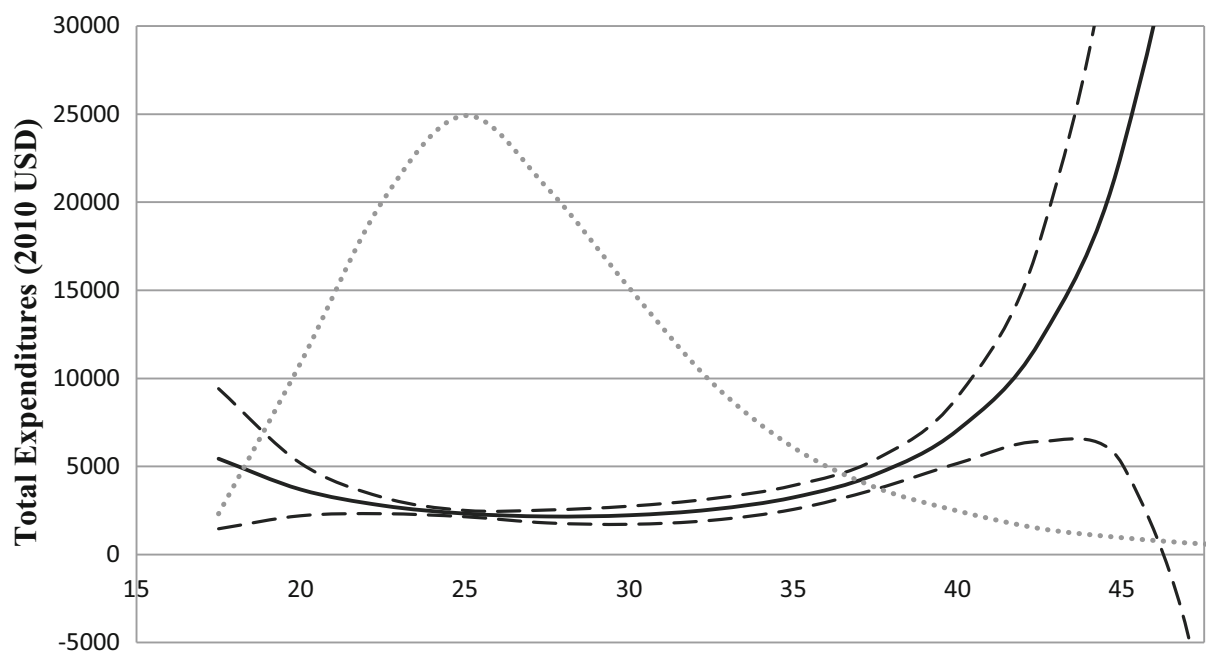

Body Mass Index

Table 1 Predicted change in total annual medical expenditures (\$US) from the instrumental variables model

\begin{tabular}{|c|c|c|c|c|}
\hline \multirow[t]{2}{*}{ Starting BMI $\left(\mathrm{kg} / \mathrm{m}^{2}\right)$} & \multicolumn{4}{|l|}{ Reduction in BMI } \\
\hline & $5 \%$ & $10 \%$ & $15 \%$ & $20 \%$ \\
\hline 30 & $69.35(59.76)$ & $56.18(132.81)$ & $-41.36(229.27)$ & $-234.91(365.29)$ \\
\hline 31 & $130.67(56.80)$ & $169.27(122.07)$ & $120.11(205.09)$ & $-23.22(319.48)$ \\
\hline 32 & $202.24(57.31)$ & $297.58(117.11)$ & $290.53(199.53)$ & $203.35(286.04)$ \\
\hline 33 & $288.31(63.01)$ & $448.01(119.78)$ & $\mathbf{5 0 1 . 2 8}(182.83)$ & $455.02(264.22)$ \\
\hline 34 & 394.43 (76.79) & $629.35(134.14)$ & $740.61(189.50)$ & $736.68(265.56)$ \\
\hline 35 & $\mathbf{5 2 8 . 0 4}(102.64)$ & $853.15(166.56)$ & $\mathbf{1 , 0 3 0 . 0 7}(216.78)$ & 1,086.61 (269.76) \\
\hline 36 & $699.23(146.01)$ & $\mathbf{1 , 1 3 4 . 8 6}(225.48)$ & 1,388.09 (275.49) & $\mathbf{1 , 5 0 2 . 4 8}(316.87)$ \\
\hline 37 & $921.94(215.07)$ & $\mathbf{1 , 4 9 5 . 4 7}(322.58)$ & $\mathbf{1 , 8 3 9 . 4 4}(379.6)$ & 2,018.76 (414.56) \\
\hline 38 & 1,215.61 (322.70) & $\mathbf{1 , 9 6 3 . 9 0}(475.54)$ & $\mathbf{2 , 4 1 7 . 8 4}(548.69)$ & 2,671.80 (583.99) \\
\hline 39 & $\mathbf{1 , 6 0 7 . 6 5}(489.36)$ & $\mathbf{2 , 5 8 0 . 4 3}(712.26)$ & 3,169.87 (813.06) & $\mathbf{3 , 5 1 1 . 4 2}(855.9)$ \\
\hline 40 & $\mathbf{2 , 1 3 7 . 1 5}(747.78)$ & $\mathbf{3 , 4 0 1 . 8 2}(1,077.11)$ & $\mathbf{4 , 1 6 0 . 5 6}(1,220.93)$ & 4,606.71 $(1,279.12)$ \\
\hline 41 & $\mathbf{2 , 8 6 0 . 3 6}(1,150.60)$ & 4,508.81 $(1,640.91)$ & $\mathbf{5 , 4 8 1 . 7 2}(1,849.27)$ & $\mathbf{6 , 0 5 4 . 7 1}(1,932.15)$ \\
\hline 42 & $\mathbf{3 , 8 5 9 . 0 8}(1,783.44)$ & $\mathbf{6 , 0 1 7 . 4 5}(2,517.59)$ & 7,264.29 $(2,821.51)$ & 7,993.11 $(2,941.33)$ \\
\hline 43 & $\mathbf{5 , 2 5 3 . 4 1}(2,787.22)$ & $\mathbf{8 , 0 9 6 . 2 4}(3,892.47)$ & $\mathbf{9 , 6 9 7 . 0 3}(4,337.4)$ & $\mathbf{1 0 , 6 1 9 . 5 1}(4,510.97)$ \\
\hline 44 & $7,221.58(4,397.01)$ & $\mathbf{1 0 , 9 9 2 . 2 9}(6,070.94)$ & $\mathbf{1 3 , 0 5 4 . 8 4}(6,724.18)$ & $\mathbf{1 4 , 2 2 0 . 4 6}(6,975.22)$ \\
\hline 45 & $10,030.69(7,010.71)$ & $15,071.78(9,563.36)$ & $\mathbf{1 7 , 7 4 2 . 2 7}(10,525.56)$ & $\mathbf{2 0 , 2 2 9 . 0 5}(11,030.17)$ \\
\hline
\end{tabular}

Data are from the MEPS 2000-2010 [18]. The estimates are from a two-part model of instrumental variables with linear and quadratic terms for BMI. Table cells contain the marginal effect of a reduction of BMI of the given magnitude, and the survey-adjusted standard errors in parentheses. Bold marginal effects are statistically significant at the $95 \%$ level. $N=41,435$

$B M I$ body mass index, MEPS Medical Expenditure Panel Survey

The nonlinearity of medical expenditures over BMI is such that, for any given reduction in BMI, cost savings are greater among the class 3 obese (BMI $\geq 40 \mathrm{~kg} / \mathrm{m}^{2}$ ) than among the class 2 obese $\left(35 \mathrm{~kg} / \mathrm{m}^{2} \leq \mathrm{BMI}<40 \mathrm{~kg} / \mathrm{m}^{2}\right)$, and in turn the savings among the class 2 obese are much greater than those among the class 1 obese $(30 \mathrm{~kg}$ / $\mathrm{m}^{2} \leq \mathrm{BMI}<35 \mathrm{~kg} / \mathrm{m}^{2}$ ). For example, a $10 \%$ reduction of BMI is associated with annual savings of $\$$ US10,992 in medical care costs if the starting BMI is $44 \mathrm{~kg} / \mathrm{m}^{2}$, a savings of $\$ U S 3,402$ if the starting BMI is $40 \mathrm{~kg} / \mathrm{m}^{2}$, a savings of \$US853 if the starting BMI is $35 \mathrm{~kg} / \mathrm{m}^{2}$, and no statistically significant change in medical expenditures if the 
starting BMI is $30 \mathrm{~kg} / \mathrm{m}^{2}$. Put another way, the savings associated with a given reduction in weight can be nearly 13 times greater for those with a BMI of $44 \mathrm{~kg} / \mathrm{m}^{2}$ than for those with a BMI of $35 \mathrm{~kg} / \mathrm{m}^{2}$.

A second observation from Fig. 1 is that the annual medical care costs of the class 1 obese $(30 \mathrm{~kg} /$ $\mathrm{m}^{2} \leq \mathrm{BMI}<35 \mathrm{~kg} / \mathrm{m}^{2}$ ) are not that much higher than those of the healthy weight or overweight. For individuals with a BMI of $30 \mathrm{~kg} / \mathrm{m}^{2}$ (just at the threshold of obesity), reductions in BMI do not imply statistically significant changes in medical expenditures. In fact, the point estimates of the savings associated with a reduction of 15 or $20 \%$ from a BMI of $30 \mathrm{~kg} / \mathrm{m}^{2}$ imply negative savingsthat is, that medical expenditures would be higher if subjects lost that much weight. These estimates are not statistically different from zero, but illustrate that medical expenditures do not dramatically jump higher at the threshold for obesity $\left(\mathrm{BMI}=30 \mathrm{~kg} / \mathrm{m}^{2}\right)$; instead, as Table 1 shows, they rise at first slowly, and then more quickly, within the obese category $\left(\mathrm{BMI} \geq 30 \mathrm{~kg} / \mathrm{m}^{2}\right.$ ). These patterns of medical care costs over BMI are consistent with the patterns of mortality risk over BMI, which show that those just over the threshold of obesity do not have higher mortality risk than individuals who are not obese, but mortality risk rises sharply with BMI in the morbidly obese range (see, for example, Flegal et al. [37] and Mehta and Chang [38]).

A third observation, also based on the nonlinearity of annual medical expenditures over BMI, is that doubling the weight loss does not double the savings. (This is observed by looking across the columns within a given row of a table.) For example, in Table 1, a person with a BMI of $40 \mathrm{~kg} / \mathrm{m}^{2}$ who experienced a weight loss of $5 \%$ is expected to experience a reduction in medical care costs of \$US2,137, but doubling the weight loss to $10 \%$ does not double the expected savings-it increases only $59.2 \%$, to $\$ \mathrm{US} 3,402$. Doubling the weight loss yet again to $20 \%$ raises the expected savings by only $35.4 \%$ to \$US4,607. Because medical expenditures rise exponentially with BMI in the obese region, the initial $5 \%$ weight loss results in more savings than subsequent additional increments of $5 \%$ weight loss. The largest incremental medical care cost savings are seen with a 5 and $10 \%$ weight loss.

\subsection{Robustness Checks: Alternate Instrumental Variable (IV) Specifications}

The IV model controls for BMI and BMI squared. To investigate the robustness of the results, we also estimated models with different specifications. This section describes the result of four robustness checks.

First, we estimated an IV model that controls only for linear BMI (not its square); restricting the flexibility of the functional form in this way results in an over-estimation of the marginal effects up to BMI values around 36 , and an underestimation of the marginal effects for BMI values above that threshold.

Second, we also sought to estimate a model that was more flexible and controlled for BMI, BMI squared, and BMI cubed, but this model did not converge. Previously published estimates from such a model that were estimated using data from 2000 to 2005 confirm the robustness of our finding that medical expenditures are J-shaped over BMI [17].

Third, we estimated IV models using a different version of the instrument; instead of using the BMI of the oldest child, we used the BMI of the youngest child. We found that the marginal effects of a 5,10 , and $15 \%$ change in BMI were very similar over most of the BMI range, and approximately 15-20\% smaller at the upper end of the BMI range. However, the standard errors of these marginal effects are larger, although most of the marginal effects still have a $p$ value of $<0.10$. This increase in the standard errors is a result of the instrument being less powerful, reflected in a lower $F$ statistic of the instrument in the first stage of the IV model.

In our IV model, we excluded income from the set of regressors because income is partly affected by weight (see, for example, Cawley [24]), and our objective was to estimate the total effect of obesity on medical expenditures through all channels, including income. As a fourth robustness check, we estimated models that control for the $\log$ of family income and found that it caused the predicted expenditure curve to flatten somewhat. This made little difference along most of the BMI distribution, but at the upper end of the BMI distribution the marginal effects were roughly one-third smaller.

\subsection{Extension 1: Results for Those With and Without Diabetes}

We estimated models for two subpopulations of interest: those without diabetes, and those with diabetes. Figures 2 and 3 plot predicted medical care costs for those without diabetes and those with diabetes, by BMI unit. Because of data limitations, the model we estimated contains only BMI (not BMI squared), and to best fit the nonlinear increase in medical expenditures in the obese range, we excluded the underweight and healthy weight (i.e. those with BMI under $25 \mathrm{~kg} / \mathrm{m}^{2}$ ). For this reason, the estimates for those with and without diabetes should not be compared with those for the full sample, only with each other.

Respondents without diabetes are estimated to have a largely linear relationship between BMI and medical care expenditures, with an uptick in slope occurring at 
Fig. 2 Predicted total annual medical expenditures from the instrumental variables model for those without type 2 diabetes. Data: Medical Expenditure Panel Survey (MEPS) 2000-2010 [18]. Expenditures are in \$US, year 2010 values. Dashed lines represent $95 \%$ confidence intervals, which have been adjusted for the complex design of the MEPS. Medical expenditures are denoted by the solid line and are measured on the left axis. The dotted line indicates the distribution of individuals in the population

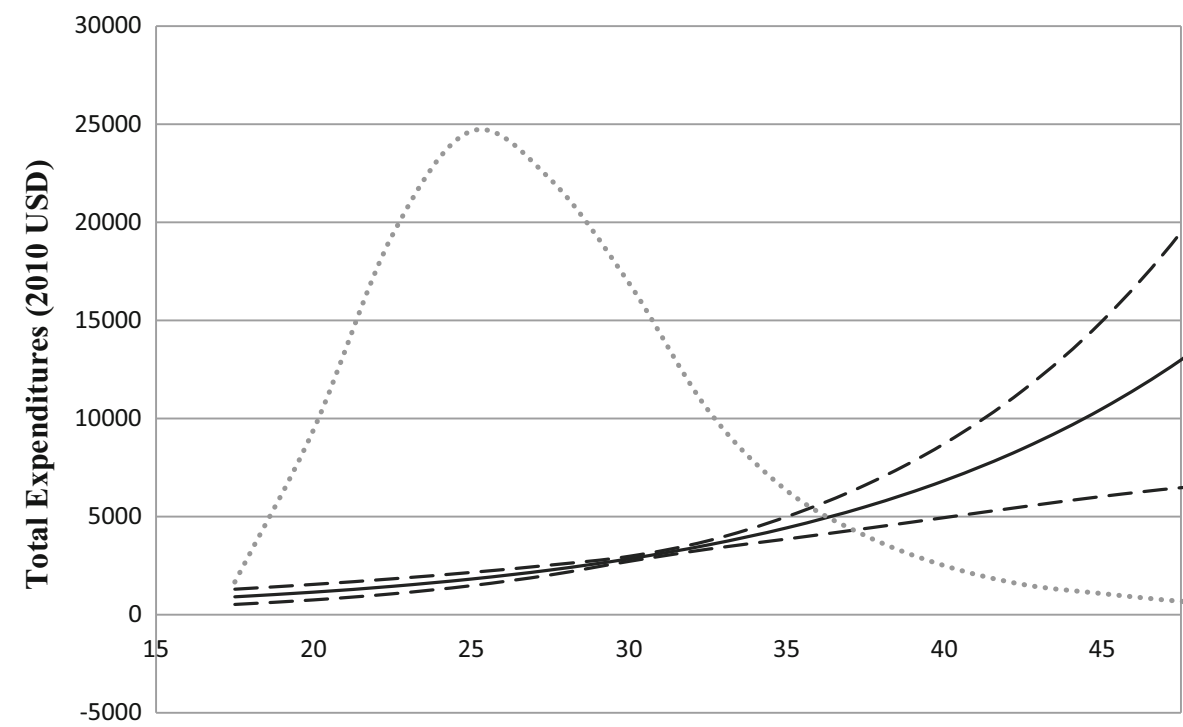

Body Mass Index
Fig. 3 Predicted total annual medical expenditures from the instrumental variables model for those with type 2 Diabetes. Data: Medical Expenditure Panel Survey (MEPS) 2000-2010 [18]. Expenditures are in \$US, year 2010 values. Dashed lines represent $95 \%$ confidence intervals, which have been adjusted for the complex design of the MEPS. Medical expenditures are denoted by the solid line and are measured on the left axis. The dotted line indicates the distribution of individuals in the population

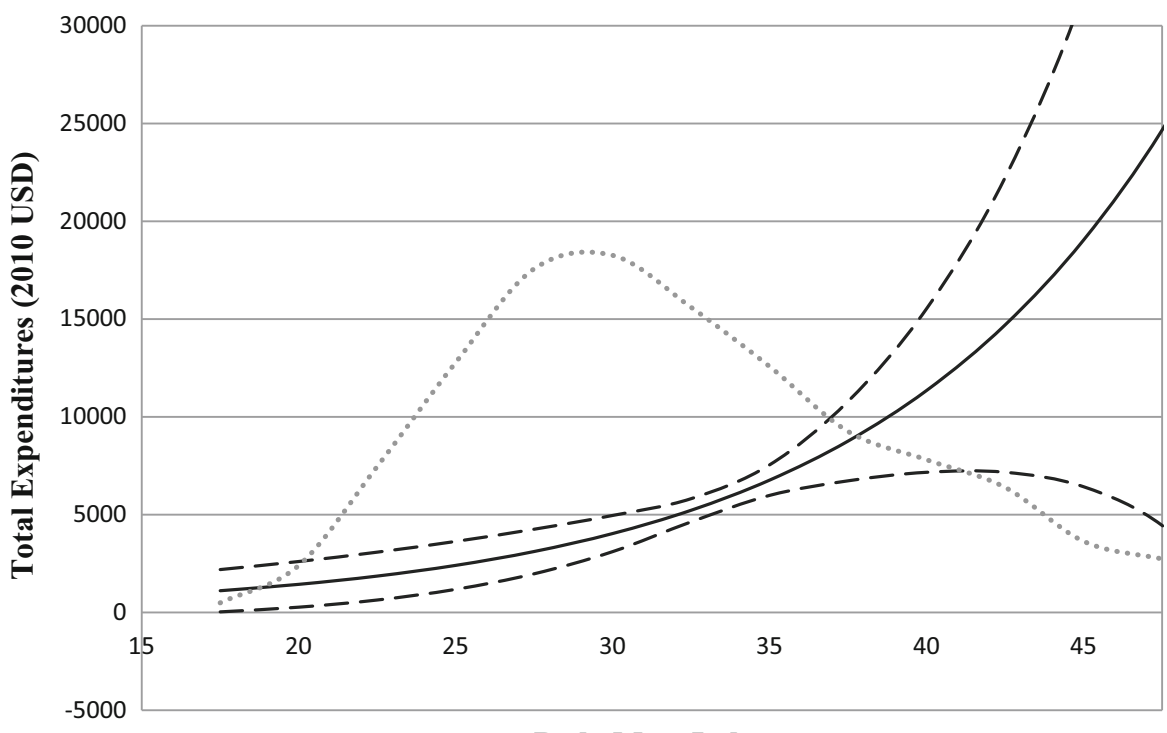

Body Mass Index approximately $\mathrm{BMI}=35 \mathrm{~kg} / \mathrm{m}^{2}$. Respondents with diabetes have a much more pronounced nonlinear relationship, with an exponential increase occurring at approximately $\mathrm{BMI}=30 \mathrm{~kg} / \mathrm{m}^{2}$. At very high levels of BMI $\left(\mathrm{BMI}>42 \mathrm{~kg} / \mathrm{m}^{2}\right)$, the large differences in costs between respondents with and without diabetes are not statistically significant because of the small sample sizes and lack of power. As a result, estimates at higher BMI levels should be interpreted cautiously.

For the samples of those with and without diabetes, as for the sample of all adults, the nonlinearity in the relationship between BMI and total medical care expenditures 
implies that potential cost reductions from a specific reduction in BMI will vary depending on the starting BMI value. Tables 2 and 3 describe the impact of $5,10,15$, and $20 \%$ BMI reductions for a range of starting BMI values for respondents without and with diabetes. As can be seen in Table 2, the annual reduction in medical care costs achievable with a $10 \%$ BMI reduction for respondents without diabetes varies fourfold depending on the initial BMI; e.g. a starting BMI $=30 \mathrm{~kg} / \mathrm{m}^{2}$ implies a cost saving of $\$$ US496, and a starting BMI $=45 \mathrm{~kg} / \mathrm{m}^{2}$ implies an annual cost saving of $\$ \mathrm{US} 1,838$. Among respondents with diabetes, the cost savings, as expected, were uniformly larger, as seen in Table 3. In this group, the annual reduction in medical care costs achievable with a $10 \%$ reduction in weight among respondents with initial BMI at $30 \mathrm{~kg} / \mathrm{m}^{2}$ is $\$ \mathrm{US} 1,076$ versus $\$ \mathrm{US7}, 093$ for respondents with BMI of $45 \mathrm{~kg} / \mathrm{m}^{2}$, which is nearly a sevenfold difference.

As is apparent from a comparison of Tables 2 and 3 or Figs. 2 and 3, the estimated annual medical care costs of respondents with diabetes uniformly exceed those without diabetes; this difference starts small at lower BMI levels and is not statistically significant prior to the range of BMI $>30 \mathrm{~kg} / \mathrm{m}^{2}$. However, the gap widens in the obese range of BMI. This is shown in Fig. 4.
4.5 Extension 2: Results for Prescription Drug Costs Only

Table 4 presents results specific to prescription drug costs for all adults. For an individual with a BMI of $40 \mathrm{~kg} / \mathrm{m}^{2}$, a weight loss of $5 \%$ is expected to result in a \$US402 reduction in annual prescription drug costs, a $10 \%$ weight loss saves \$US679, a $15 \%$ weight loss saves \$US869, and a $20 \%$ weight loss saves \$US999. Prescription drug costs, like overall medical costs, rise exponentially with BMI in individuals with severe obesity, with the result that doubling the weight loss less than doubles the savings.

\subsection{Extension 3: Results from Non-IV Models That Do Not Address Endogeneity and Reporting Error}

Previous studies of the change in medical care costs with BMI have used the same data (MEPS); the key difference of this analysis is the analytic technique: IVs. In order to determine the impact of alternative estimation techniques, we also estimated models of total medical expenditures that do not use the IV method.

While these models have the disadvantage of suffering an unknown degree of omitted variables bias and reporting error bias, they have the important advantage of a larger

Table 2 Predicted change in total annual medical expenditures (\$US) from the instrumental variables model for those without type 2 diabetes

\begin{tabular}{|c|c|c|c|c|}
\hline \multirow[t]{2}{*}{ Starting BMI $\left(\mathrm{kg} / \mathrm{m}^{2}\right)$} & \multicolumn{4}{|c|}{ Reduction in BMI } \\
\hline & $5 \%$ & $10 \%$ & $15 \%$ & $20 \%$ \\
\hline 30 & $259.74(68.37)$ & $495.69(123.79)$ & $709.96(168.08)$ & $904.51(202.81)$ \\
\hline 31 & $285.66(80.48)$ & $\mathbf{5 4 4 . 3 7}(145.76)$ & 778.60 (198.) & $990.62(239.1)$ \\
\hline 32 & 313.82 (94.25) & $\mathbf{5 9 7 . 1 6}(170.7)$ & $880.60(238.52)$ & $\mathbf{1 , 0 8 3 . 7 0}(280.24)$ \\
\hline 33 & 344.37 (109.85) & $654.37(198.95)$ & $933.33(270.36)$ & $1,184.29(326.75)$ \\
\hline 34 & $377.53(127.51)$ & $\mathbf{7 1 6 . 3 3}(230.87)$ & $\mathbf{1 , 0 2 0 . 3 0}(313.72)$ & $\mathbf{1 , 3 2 0 . 6 2}(385.79)$ \\
\hline 35 & 413.48 (147.44) & $783.42(266.86)$ & $\mathbf{1 , 1 1 4 . 3 2}(362.57)$ & $\mathbf{1 , 4 1 0 . 2 1}(438.25)$ \\
\hline 36 & $452.44(169.91)$ & $\mathbf{8 5 6 . 0 3}(307.38)$ & $\mathbf{1 , 2 1 5 . 9 3}(417.48)$ & $\mathbf{1 , 5 3 6 . 7 7}(504.57)$ \\
\hline 37 & $494.65(195.18)$ & $934.57(352.89)$ & $\mathbf{1 , 3 2 5 . 6 8}$ & $\mathbf{1 , 6 7 3 . 2 8}(578.91)$ \\
\hline 38 & $\mathbf{5 4 0 . 3 7}(223.56)$ & $\mathbf{1 , 0 1 9 . 4 9}(403.95)$ & $\mathbf{1 , 4 4 4 . 1 7}(548.15)$ & $\mathbf{1 , 8 2 0 . 4 7}(662.13)$ \\
\hline 39 & $\mathbf{5 8 9 . 8 5}(255.4)$ & $\mathbf{1 , 1 1 1 . 2 7}(461.13)$ & 1,572.06 (625.39) & $\mathbf{1 , 9 7 9 . 1 2}(755.11)$ \\
\hline 40 & 643.39 (291.05) & $\mathbf{1 , 2 1 0 . 4 4}(525.08)$ & $\mathbf{1 , 7 1 0 . 0 3}(711.67)$ & $\mathbf{2 , 1 5 0 . 0 5}(858.87)$ \\
\hline 41 & 701.30 (330.92) & $\mathbf{1 , 3 1 7 . 5 4}(596.51)$ & $\mathbf{1 , 8 5 8 . 8 4}(807.91)$ & $\mathbf{2 , 3 3 4 . 1 4}(974.5)$ \\
\hline 42 & $763.92(375.46)$ & $\mathbf{1 , 4 3 3 . 1 6}(676.19)$ & $\mathbf{2 , 0 1 9 . 2 6}(915.15)$ & 2,532.36 $(1,103.19)$ \\
\hline 43 & $831.60(425.17)$ & $\mathbf{1 , 5 5 7 . 9 6}(764.98)$ & $\mathbf{2 , 1 9 2 . 1 6}(1,034.49)$ & $\mathbf{2 , 7 4 5 . 7 0}(1,246.24)$ \\
\hline 44 & $904.74(480.57)$ & $\mathbf{1 , 6 9 2 . 6 0}(863.81)$ & $\mathbf{2 , 3 7 8 . 4 4}(1,167.16)$ & $\mathbf{2 , 9 7 5 . 2 5}(1,405.1)$ \\
\hline 45 & $983.73(542.26)$ & $\mathbf{1 , 8 3 7 . 8 1}(973.7)$ & $\mathbf{2 , 5 7 9 . 0 7}(1,314.49)$ & $\mathbf{3 , 9 4 8 . 7 7}(1,845.49)$ \\
\hline
\end{tabular}

Data are from the MEPS 2000-2010 [18]. The estimates are from a two-part model of instrumental variables with a linear term for BMI. Table cells contain the marginal effect of a reduction of BMI of the given magnitude, and the survey-adjusted standard errors in parentheses. Bold marginal effects are statistically significant at the $95 \%$ level. $N=26,707$

$B M I$ body mass index, MEPS Medical Expenditure Panel Survey 
Table 3 Predicted change in total annual medical expenditures (\$US) from the instrumental variables model for those with type 2 diabetes

\begin{tabular}{|c|c|c|c|c|}
\hline \multirow[t]{2}{*}{ Starting BMI $\left(\mathrm{kg} / \mathrm{m}^{2}\right)$} & \multicolumn{4}{|l|}{ Reduction in BMI } \\
\hline & $5 \%$ & $10 \%$ & $15 \%$ & $20 \%$ \\
\hline 30 & $\mathbf{5 7 9 . 7 0}(112.32)$ & 1,076.01 (186.11) & $\mathbf{1 , 5 0 0 . 9 3}(230.92)$ & $\mathbf{1 , 8 6 4 . 7 3}(254.44)$ \\
\hline 31 & $\mathbf{6 6 2 . 7 0}(148.38)$ & $\mathbf{1 , 2 2 7 . 1 4}(247.62)$ & $\mathbf{1 , 7 0 7 . 8 9}(309.72)$ & $\mathbf{2 , 1 1 7 . 3 6}(344.19)$ \\
\hline 32 & 756.79 (192.86) & 1,398.05 (323.68) & 2,003.21 (415.4) & 2,401.81 (456.44) \\
\hline 33 & $863.41(247.33)$ & $\mathbf{1 , 5 9 1 . 2 2}(416.89)$ & 2,204.74 (527.75) & 2,721.91 (594.73) \\
\hline 34 & 984.13 (313.65) & $\mathbf{1 , 8 0 9 . 4 4}(530.36)$ & $\mathbf{2 , 5 0 1 . 5 4}(674.12)$ & $\mathbf{3 , 1 4 3 . 7 4}(771.08)$ \\
\hline 35 & $\mathbf{1 , 1 2 0 . 7 8}(394.04)$ & $\mathbf{2 , 0 5 5 . 8 1}(667.78)$ & $\mathbf{2 , 8 3 5 . 8 9}(851.36)$ & 3,486.69 (967.86) \\
\hline 36 & $\mathbf{1 , 2 7 5 . 3 5}(491.09)$ & $\mathbf{2 , 3 3 3 . 8 5}(833.51)$ & $\mathbf{3 , 2 1 2 . 3 7}(1,064.97)$ & $\mathbf{3 , 9 4 1 . 5 2}(1,214.22)$ \\
\hline 37 & $\mathbf{1 , 4 5 0 . 1 3}(607.88)$ & $\mathbf{2 , 6 4 7 . 4 8}(1,032.66)$ & $\mathbf{3 , 6 3 6 . 1 0}(1,321.44)$ & $\mathbf{4 , 4 5 2 . 3 9}(1,509.86)$ \\
\hline 38 & 1,647.66 (748.04) & $\mathbf{3 , 0 0 1 . 0 8}(1,271.27)$ & $\mathbf{4 , 1 1 2 . 8 0}(1,628.34)$ & $\mathbf{5 , 0 2 5 . 9 8}(1,863.38)$ \\
\hline 39 & $\mathbf{1 , 8 7 0 . 8 0}(915.82)$ & $\mathbf{3 , 3 9 9 . 5 8}(1,556.39)$ & 4,648.86 $(1,994.58)$ & $\mathbf{5 , 6 6 9 . 7 4}(2,284.85)$ \\
\hline 40 & $\mathbf{2 , 1 2 2 . 7 7}(1,116.24)$ & $\mathbf{3 , 8 4 8 . 5 0}(1,896.3)$ & $\mathbf{5 , 2 5 1 . 4 4}(2,430.54)$ & $\mathbf{6 , 3 9 1 . 9 6}(2,786.03)$ \\
\hline 41 & $\mathbf{2 , 4 0 7 . 1 8}(1,355.18)$ & 4,354.01 $(2,300.72)$ & $\mathbf{5 , 9 2 8 . 5 3}(2,948.39)$ & $\mathbf{7 , 2 0 1 . 9 3}(3,380.62)$ \\
\hline 42 & $\mathbf{2 , 7 2 8 . 0 8}(1,639.55)$ & $\mathbf{4 , 9 2 3 . 0 4}(2,780.99)$ & $\mathbf{6 , 6 8 9 . 0 7}(3,562.33)$ & $\mathbf{8 , 1 0 9 . 9 9}(4,084.63)$ \\
\hline 43 & $\mathbf{3 , 0 9 0 . 0 1}(1,977.47)$ & $\mathbf{5 , 5 6 3 . 3 3}(3,350.43)$ & 7,543.06 $(4,288.95)$ & $\mathbf{9 , 1 2 7 . 6 8}(4,916.71)$ \\
\hline 44 & $\mathbf{3 , 4 9 8 . 0 6}(2,378.46)$ & $\mathbf{6 , 2 8 3 . 5 6}(4,024.61)$ & $\mathbf{8 , 5 0 1 . 6 3}(5,147.62)$ & $\mathbf{1 0 , 2 6 7 . 8 7}(5,898.58)$ \\
\hline 45 & $\mathbf{3 , 9 5 7 . 9 7}(2,853.69)$ & $\mathbf{7 , 0 9 3 . 4 1}(4,821.72)$ & $\mathbf{9 , 5 7 7 . 2 6}(6,160.95)$ & $\mathbf{1 3 , 5 4 7 . 6 2}(7,779.4)$ \\
\hline
\end{tabular}

Data are from the MEPS 2000-2010 [18]. The model is a one-part model of instrumental variables with a linear term for BMI. Table cells contain the marginal effect of a reduction of BMI of the given magnitude, and the survey-adjusted standard errors in parentheses. Bold marginal effects are statistically significant at the $95 \%$ level. $N=2,308$

$B M I$ body mass index, MEPS Medical Expenditure Panel Survey

sample. This is because they can be estimated using the entire MEPS sample; the sample does not need to be restricted to adults with a biological child in the household, as is required for the IV model. As a result, the non-IV model can be estimated with a sample of 172,066 individuals, compared with the sample of 41,435 for the IV model. That increased sample size enables more precise estimates.

The non-IV results are presented in Appendix Table 1 (see the Electronic Supplementary Material [ESM] for all appendices) for the pooled full sample of adults, Appendix Table 2 for the pooled IV sample of adults (i.e. the non-IV model is estimated using the IV sample for the sake of comparability), Appendix Table 3 for those without diabetes, Appendix Table 4 for those with diabetes, and Appendix Table 5 for prescription drug expenditures. Overall, IV models tend to predict greater savings from weight loss than do non-IV models, and this difference increases with BMI. In other words, the IV models estimate that medical expenditures rise more steeply with BMI than do non-IV models. For example, a $5 \%$ weight loss starting from a BMI of $31 \mathrm{~kg} / \mathrm{m}^{2}$ is expected to lower annual medical expenditures by \$US131 per year in the IV model (Table 1), which is roughly $11 \%$ higher than the estimate of \$US118 from the non-IV model (Appendix Table 1). However, if the starting BMI is $40 \mathrm{~kg} / \mathrm{m}^{2}$, that same $5 \%$ decrease in weight implies a \$US2,137 annual savings according to the IV model, which is over six times larger than the savings of \$US313 implied by the non-IV model. Clearly, addressing endogeneity and measurement error makes a substantial difference at high levels of BMI.

The non-IV model estimates of the difference in medical expenditures by BMI level are greater when the model is estimated using the full sample (Appendix Table 1) than the IV sample (Appendix Table 2). One explanation is that the condition to be included in the IV sample-having biological children-results in the IV sample being healthier than average; we return to this point in the Discussion section. If one wishes to know the correlation (rather than causal effect), then the results from the non-IV model estimated using the full sample (Appendix Table 1) are preferable to those estimated using the IV sample (Appendix Table 2) because the non-IV sample is so much larger $(N=172,066$ vs. 41,435$)$ and thus the estimates are more precise.

\subsection{Extension 4: The Medical Care Costs of Adult} Obesity: Per Case and Aggregate for the USA

In order to calculate the effect of obesity on medical care costs, both per obese individual and for the US as a whole, we estimate IV models in which the endogenous regressor is an indicator variable for obesity, rather than BMI and BMI squared. This represents an update of a previous study 
Fig. 4 Predicted total annual medical expenditures from the instrumental variables model. Data: Medical Expenditure Panel Survey (MEPS) 2000-2010 [18]. Expenditures are in \$US, year 2010 values. Dashed lines represent $95 \%$ confidence intervals, which have been adjusted for the complex design of the MEPS. Medical expenditures are denoted by the solid line and are measured on the left axis. The dotted line indicates the distribution of individuals in the population

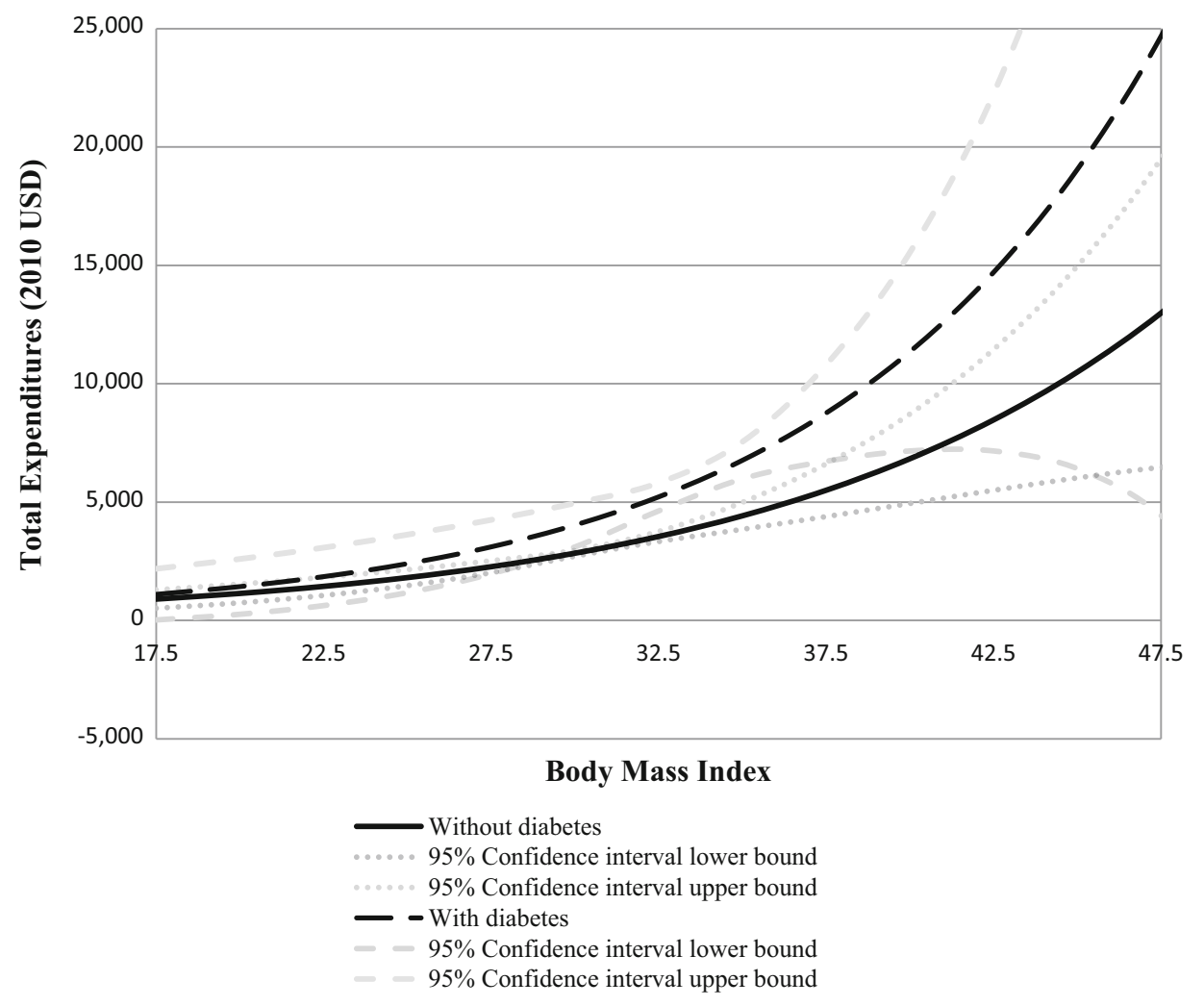

[17], which estimated identical models using MEPS data for 2000-2005, whereas this paper uses the longer MEPS panel of 2000-2010.

The results of this modified IV model indicate that obesity raises annual medical care costs by $\$$ US3,508 per year (year 2010 values), with a standard error of \$US806. Because the regression model uses an indicator variable for obesity, this represents the additional costs of the obese relative to the non-obese (as opposed to only the healthy weight). The results of the IV model imply that, for the US as a whole, adult obesity raised annual medical care costs by $\$$ US315.8 billion in $2010 .^{10}$

\footnotetext{
10 The aggregate costs of adult obesity in the US were calculated as follows. Our estimates indicate that, in 2010, obesity raised medical care costs by $\$$ US44.3 billion among adults with biological children (i.e. those who constitute our IV sample). Under the (admittedly, strong) assumption that the effect of obesity in our subpopulation generalizes to the full non-institutionalized population of adults aged 18 and older, we scaled the costs in the subpopulation used to estimate our model up to the entire adult population by multiplying the subpopulation aggregate costs by the ratio of the US population of adults to the US population of adults with biological children, or $\$$ US44.3 billion $*(233.7$ million $/ 32.8$ million $)=\$ 315.8$ billion. The population counts are derived from the MEPS sample and sample weights.
}

\section{Discussion}

The increase in the prevalence of obesity is an important public health issue, with major cost implications for the healthcare system. Healthcare providers, payers, and employers must assess the savings associated with weight reduction in different populations. Clinical research has established that a sustained weight loss of 5-10\% in obese individuals has significant health benefits, including improvements in a number of comorbidities such as blood glucose levels, blood pressure, cholesterol levels, and obstructive sleep apnea (e.g. Tuomilehto et al. [39]; Knowler et al. [40]).

This paper provides the first estimates of the savings in medical expenditures associated with specific reductions in BMI from specific starting values of BMI that address three problems: the endogeneity of BMI, reporting error in weight and height, and the nonlinearity of medical expenditures over BMI. The results indicate that substantial medical expenditure savings can be achieved by interventions that can reduce BMI by $5-10 \%$. A comparison of model results indicates that the causal effect of BMI reduction that is measured by IV models is greater than the association that is measured by non-IV models that have been used in the past. This paper also provides estimates for those with and without diabetes, and estimates the savings in prescription drug costs as well as in total medical care costs. 
Table 4 Predicted change in annual prescription drug expenditures (\$US) from instrumental variables model

\begin{tabular}{|c|c|c|c|c|}
\hline \multirow[t]{2}{*}{ Starting BMI $\left(\mathrm{kg} / \mathrm{m}^{2}\right)$} & \multicolumn{4}{|l|}{ Reduction in BMI } \\
\hline & $5 \%$ & $10 \%$ & $15 \%$ & $20 \%$ \\
\hline 30 & $42.65(22.36)$ & $69.40(47.48)$ & 81.85 (76.68) & 80.63 (112.11) \\
\hline 31 & $\mathbf{5 6 . 2 0}(21.68)$ & $93.72(45.65)$ & $115.06(73.01)$ & 121.55 (105.58) \\
\hline 32 & $72.15(21.27)$ & $122.00(44.30)$ & $154.24(73.15)$ & $167.98(100.33)$ \\
\hline 33 & $91.11(21.30)$ & $155.24(43.50)$ & $197.58(67.94)$ & 221.37 (96.05) \\
\hline 34 & $113.81(22.28)$ & $194.69(43.75)$ & $\mathbf{2 4 9 . 7 0}(66.71)$ & $284.48(95.64)$ \\
\hline 35 & $141.21(25.24)$ & 241.83 (46.27) & $\mathbf{3 1 1 . 4 5}(67.40)$ & $356.36(90.93)$ \\
\hline 36 & $174.46(31.67)$ & 298.57 (53.32) & 385.14 (72.31) & $442.69(92.51)$ \\
\hline 37 & $215.05(43.21)$ & 367.25 (67.92) & $473.67(85.24)$ & $\mathbf{5 4 5 . 6 5}(101.31)$ \\
\hline 38 & 264.85 (61.66) & 450.82 (93.30) & $\mathbf{5 8 0 . 6 3}(110.82)$ & 669.21 (123.05) \\
\hline 39 & 326.28 (89.40) & 553.07 (133.06) & 710.57 (153.85) & 818.39 (164.05) \\
\hline 40 & 402.44 (129.87) & 678.80 (192.07) & $869.26(219.93)$ & 999.50 (230.75) \\
\hline 41 & 497.39 (188.09) & $834.22(277.44)$ & $\mathbf{1 , 0 6 4 . 0 8}(316.89)$ & $\mathbf{1 , 2 2 0 . 5 8}(331.22)$ \\
\hline 42 & $616.41(271.41)$ & $\mathbf{1 , 0 2 7 . 3 8}(399.50)$ & $\mathbf{1 , 3 0 4 . 5 3}(456.20)$ & $\mathbf{1 , 4 9 1 . 9 3}(477.15)$ \\
\hline 43 & 766.49 (390.57) & 1,268.76 (573.32) & $\mathbf{1 , 6 0 2 . 9 3}(654.59)$ & $\mathbf{1 , 8 2 6 . 8 4}(685.79)$ \\
\hline 44 & $956.87(561.32)$ & $\mathbf{1 , 5 7 2 . 1 6}(820.82)$ & $\mathbf{1 , 9 7 5 . 3 7 ~ ( 9 3 6 . 4 3 ) ~}$ & $\mathbf{2 , 2 4 2 . 5 7 ~ ( 9 8 2 . 3 6 ) ~}$ \\
\hline 45 & 1,199.84 (806.96) & $\mathbf{1 , 9 5 5 . 7 8}(1,174.15)$ & $\mathbf{2 , 4 4 2 . 9 3}(1,337.25)$ & $\mathbf{3 , 0 2 3 . 5 7}(1,424.94)$ \\
\hline
\end{tabular}

Data are from the MEPS 2000-2010 [18]. The estimates are from a two-part model of instrumental variables with linear and quadratic terms for BMI. Table cells contain the marginal effect of a reduction of BMI of the given magnitude, and the survey-adjusted standard errors in parentheses. Bold marginal effects are statistically significant at the $95 \%$ level. $N=41,435$. There were 25,076 individuals with positive expenditures on prescription drugs with mean annual expenditure of $\$ 993.48$

$B M I$ body mass index, MEPS Medical Expenditure Panel Survey

The nonlinear relationship suggested by the IV analysis indicates that savings from a given percent reduction in weight increase with starting BMI within the obese range $\left(\mathrm{BMI}>30 \mathrm{~kg} / \mathrm{m}^{2}\right)$. The results also indicate that doubling the weight loss does not double the savings - there is a greater decrease in medical expenditures from the first $5 \%$ weight loss than from additional $5 \%$ increments of weight loss. Finally, the medical expenditures of individuals who are just over the threshold of obesity $\left(\mathrm{BMI}=30 \mathrm{~kg} / \mathrm{m}^{2}\right)$ are not much higher than those of individuals who are overweight. However, within the morbidly obese range of BMI, medical care costs rise exponentially.

There are several implications of this. Weight loss interventions might be initially targeted in populations where one can achieve the greatest reductions in medical care costs, i.e. to the morbidly obese, who exhibit the steepest relationship between medical expenditures and BMI. The value of interventions in these higher BMI populations appears to be much greater than for the overall population. The incremental savings from BMI reductions appear to lessen as the percent of weight lost increases, which suggests that some insurers may carefully consider the clinically and economically optimal size of weight loss when targeting obesity interventions.

An important finding of this analysis is that the nonlinear relationship between BMI and medical expenditures is more pronounced among those with diabetes than among those without diabetes. We found that the medical care costs of individuals with diabetes are greater than those without diabetes at every unit of BMI and that, at high levels of BMI, this difference amounts to thousands of dollars per year. This suggests that savings can be achieved not only through weight loss among the high BMI groups in either glycemic category (i.e. moving along the cost curve), but also by avoiding diabetes (i.e. not moving from the lower to the higher cost curve). However, we caution that this paper is able to measure the causal effect of BMI, not the causal effect of diabetes, on medical expenditures.

This paper provides updated estimates of the effect of adult obesity on medical care costs that can be used to more accurately calculate the cost effectiveness of medical treatments and public policies to prevent and reduce adult obesity. A comparison of the results of this paper with those of the previous literature indicates that adult obesity has become more expensive over time in the USA, both in aggregate and per individual. Cawley and Meyerhoefer [17] estimated that the aggregate costs of adult obesity in the USA in 2005 were \$US190.2 billion (year 2005 values). In contrast, this paper estimates that the aggregate costs of obesity in the USA in 2010 totaled \$US315.8 billion (year 2010 values). Converting the estimate for 2005 to 2010 values in order to adjust for inflation (and 
thus compare apples to apples), the aggregate costs of obesity rose from \$US213.0 billion in 2005 to \$US315.8 billion in 2010 , an increase of $48.3 \%$. As a percent of the total healthcare spending of non-institutionalized adults, this rose from $20.6 \%$ in 2005 to $27.5 \%$ in 2010. Part of this increase in the aggregate costs is due to a larger number of obese individuals, and part is due to an increase in the cost per individual.

Even if the prevalence of obesity had remained constant during that time, there would be an increase in the number of obese individuals simply because of population growth; the adult population of the USA (aged 20 and over) rose from 213.5 million in 2005 to 226.1 million in 2010 (US Census Bureau, [41]). Although the change in the prevalence of obesity during that time was not statistically significant, the point estimates indicate that it rose from $34.3 \%$ in $2005-06$ to $35.7 \%$ in $2009-10$ [2]. (These are age-adjusted prevalences, and thus do not include the increase in obesity prevalence due to the aging US population.) Combined, these figures imply that the number of obese adults (aged 20 and over) in the USA rose by 7.5 million, or $10.2 \%$, between 2005 and 2010. The increase in class 2 and class 3 obesity (which are associated with much higher medical expenditures) may have been even greater.

In addition, the costs of each obese individual rose from 2005 to 2010. Cawley and Meyerhoefer [17] estimated that adult obesity raised individual medical care costs by \$US2,741 in 2005 (year 2005 values). This paper finds that obesity raised individual medical care costs by $\$ \mathrm{US} 3,508$ in 2010. Converting the estimate for 2005 to 2010 values in order to adjust for inflation, the impact of obesity on individual medical care costs rose from \$US3,070 in 2005 to $\$$ US3,508 in 2010, an increase of $14.3 \%$. Future research should further investigate the extent to which this increase is due to increases in obesity-related co-morbidities, more intensive treatment of obesity, and changing costs of medical care (inflation in the medical care sector outstripping inflation in the economy as a whole).

The IV method results in much higher estimates of cost savings than non-IV models. This is likely due to IV's corrections for endogeneity and measurement error. Certain subgroups with a disproportionately high prevalence of obesity have reduced access to care (e.g. disadvantaged minorities and those of low socioeconomic status; see Fontaine and Bartlett [42]), and thus failure to account for this may cause attenuation bias. Reporting error in weight, which can be substantial (Cawley and Burkhauser [11]), can cause attenuation bias (Bound et al. [12], Carroll et al. [22]). The difference between the IV and non-IV models rises with $\mathrm{BMI}$ in the obese range, which may reflect both greater under-reporting of weight and a more severe problem of unobserved heterogeneity at high levels of
BMI. A direction for future research is to determine the extent to which the larger IV estimates are due to reporting error or unobserved heterogeneity.

In interpreting the magnitude of the predicted savings in medical expenditures, it may be useful to compare them with the cost of medical services. In the 2010 MEPS data, for individuals of the same age as our sample (24-64 years), the average total cost (by all payers combined) of an inpatient stay was \$US13,780, that of an outpatient department visit was \$US1,460, that of an emergency department visit was \$US1,161, that of an office visit (whether of a physician, nurse practitioner, or other medical professional) was \$US199, and filling a prescription drug averaged \$US70. Thus, for the entire sample (Table 1), one can interpret the annual savings associated with a $10 \%$ reduction in weight from a starting BMI of $40 \mathrm{~kg} / \mathrm{m}^{2}$ (\$US3,402) as roughly equal to onequarter of an inpatient stay. Thus, if a $10 \%$ weight loss from a BMI of $40 \mathrm{~kg} / \mathrm{m}^{2}$ led to one fewer hospital stay over the next 4 years, it would explain the full magnitude of the estimated savings.

The research results and discussion above are subject to important caveats and limitations. As in every application of IV, one should be wary of threats to the validity of the instrument. Our identifying assumption is that the weight of a biological child is correlated with respondent medical expenditures only because of its correlation with respondent weight. Like the previous literature to use this instrument (Cawley [24]; Kline and Tobias [25]; Smith et al. [26]; Cawley and Meyerhoefer [17]), we acknowledge that the genes that affect weight could also affect other things that directly affect residual medical care costs (pleiotropy), and the genes that affect weight may lie next to genes that directly affect residual medical care costs (proximity matters because genes are inherited in blocks). In addition, we assume that there is no systematic misreporting of child BMI by parents that is correlated with systematic misreporting of self-reported or proxy reported parental BMI. If, for example, parents who under-report their own weight consistently under- or over-report the height or weight of their children, our estimates of adult BMI on medical expenditures will be biased (Carroll et al. [22]). However, IV estimates based on powerful instruments are much less sensitive to violations of this assumption than those based on relatively weak instruments (Small and Rosenbaum [43]), and the instruments used here are unusually powerful, with $F$ statistics an order of magnitude larger than the minimum standard: 581 for the pooled sample, compared with the threshold of ten suggested by Stock et al. [29].

The MEPS provides the best available data on the medical expenditures of a nationally representative sample of Americans, but it has important limitations. It contains 
self-reported, not measured, weight and height. It contains self-reports of being diagnosed with diabetes, but not objective blood glucose tests and no ICD-9 diagnosis codes. We examined diabetes as an important co-morbidity of obesity; future research may wish to explore the role of other co-morbidities. The MEPS includes 2 years worth of data for each respondent; ideally, it would have a longerterm follow-up. Also, the MEPS data only allow us to compare the medical expenditures of people at different levels of BMI; it does not allow us to observe how medical expenditures change with changes in BMI. Thus, like the previous literature, we must assume that after weight loss one's medical expenditures equal those of the people who were already at the lower BMI.

We caution that the method of weight loss may impact the amount of medical care savings. For example, those who lose weight via bariatric surgery are likely to experience a rise in medical expenditures shortly after surgery due to follow-up visits and the risks of sepsis and infection. As another (extreme) example, if someone starved himself, he would end up at a lower BMI but would also probably be in worse health (and may have higher medical expenditures) than those at that new BMI. As such, our estimates may be more accurately described as the benefits of preventing weight gain than the savings associated with weight loss.

Another limitation is that, like the previous literature, this paper uses BMI, which is a limited measure of fatness because it does not distinguish fat from muscle [44]. Ideally, the MEPS would contain multiple measures of excess weight such as fat mass, percent body fat, and waist circumference, but we are limited to using the only measures available in the MEPS: weight and height.

The methods we use to estimate the impact of BMI on medical expenditures are parametric; as a result, they impose a functional relationship between BMI and medical expenditures that is not fully flexible. This is particularly true of the models estimated for diabetics and non-diabetics, which contain BMI but not BMI squared. The specification tests we conducted indicate that the Gamma GLM fits the data well, but using this specification does constrain the shape of the exponential relationship between BMI and medical spending more than a nonparametric model.

Another limitation stems from the nature of our IV model. To use the weight of a biological child as an instrument, we have to limit our sample to those with a biological child in their household (the MEPS only collects information on children residing in the household). People with biological children tend to be healthier than average; in Appendix Table A, they have the same probability of incurring some medical care costs $(84 \%)$ as the full sample, but they tend to incur lower costs conditional on incurring any (\$US3,372 vs. \$US4,286 for the full sample.
Thus, the local average treatment effect (LATE) measured in this paper may be the effect of obesity on medical care costs among the relatively healthy. Moreover, the LATE corresponds to variation in weight due to genetics; variation in weight due to other sources may have a different impact on medical expenditures. Each instrument in an IV model can affect a different marginal population and thus have a different LATE. Because this research relies upon a single instrument, it could be interpreted as explorative in nature; future research should seek to examine the robustness of these estimates by finding and exploiting other natural experiments that affect weight and that would be valid and powerful instruments in an IV model of medical care costs.

Despite these limitations, this paper makes an important contribution by providing the first estimates of the savings in medical expenditures associated with specific reductions in BMI from specific starting BMI, for all adults as well as people with and without diabetes separately, using methods that address the endogeneity of BMI, reporting error in weight, and the nonlinearity of the relationship. Future research could apply these methods to estimate other benefits associated with weight loss, such as decreases in job absenteeism and increased productivity while on the job.

\section{Conclusions}

The IV model indicates that obesity raises annual medical care costs by $\$ U S 3,508$ per obese individual per year, or \$US315.8 billion for the USA as a whole (both measured in 2010 values). The results of IV models are also used to construct detailed tables of the estimated medical care expenditure savings given specific reductions in BMI from specific starting values of $\mathrm{BMI}$; these tables indicate that the savings from a given percent reduction in BMI is greater the heavier the obese individual, and is greater for those with diabetes than for those without diabetes.

These estimates of the change in medical care expenditures resulting from weight loss can be used to more accurately calculate the cost effectiveness of interventions to prevent and treat obesity, and can be used by health insurers, employers, and government agencies to determine the societal savings from, and business case for, interventions that generate a specific amount of weight loss.

Acknowledgments The authors thank Novo Nordisk, Inc. for their financial support of this research. NW and $\mathrm{MH}$ are employees and stockholders of Novo Nordisk, Inc. JC, CM, and AB are paid consultants to Novo Nordisk, Inc. JC contributed to the conceptual framework, drafted manuscript sections, supervised the data analysis, revised the manuscript with input from all co-authors, and serves as the overall guarantor for the work. CM contributed to the conceptual 
framework, drafted manuscript sections, analyzed the data, reviewed and edited all drafts of the manuscript, and also serves as the overall guarantor for the work. $\mathrm{AB}$ analyzed the data. NW and $\mathrm{MH}$ contributed to the conceptual framework and reviewed and edited all drafts of the manuscript. We thank Ana Bozas, PhD, an employee of Analysis Group Inc., for formatting and editing assistance.

Open Access This article is distributed under the terms of the Creative Commons Attribution Noncommercial License which permits any noncommercial use, distribution, and reproduction in any medium, provided the original author(s) and the source are credited.

\section{References}

1. Burkhauser RV, Cawley J, Schmeiser MD. The timing of the rise in U.S. obesity varies with measure of fatness. Econ Hum Biol. 2009; 7(3):307-18.

2. Ogden CL, Carroll MD, Kit BK, Flegal KM. Prevalence of childhood and adult obesity in the United States, 2011-2012. JAMA. 2014;311(8):806-14.

3. Guh DP, Zhang W, Bansback N, Amarsi Z, Birmingham CL, Anis $\mathrm{AH}$. The incidence of co-morbidities related to obesity and overweight: a systematic review and meta-analysis. BMC Public Health. 2009;9:88.

4. Dixon JB. The effect of obesity on health outcomes. Mol Cell Endocrinol. 2010;316(2):104-8.

5. Hu FB. Obesity epidemiology. New York: Oxford University Press; 2008.

6. Winter Y, Sankowski R, Back T. Genetic determinants of obesity and related vascular diseases. Vitam Horm. 2013;91:29-48.

7. Trayhurn P, Beattie JH. Physiological role of adipose tissue: white adipose tissue as an endocrine and secretory organ. Proc Nutr Soc. 2001;60(3):329-39.

8. Calle EE, Kaaks R. Overweight, obesity and cancer: epidemiological evidence and proposed mechanisms. Nat Rev Cancer. 2004;4(8):579-91.

9. Malnick SDH, Knobler H. The medical complications of obesity. QJM. 2006;99(9):565-79.

10. McLaren L. Socioeconomic Status and Obesity. In: Cawley JHJ, editor. The Oxford handbook of the social science of obesity. New York: Oxford University Press; 2011. pp. xvi, 894.

11. Cawley J, Burkhauser R. Beyond BMI: the value of more accurate measures of fatness and obesity in social science research. NBER Working Paper No. 12291. National Bureau of Economic Research. June 2006. Available from: http://www.nber.org/ papers/w12291.pdf. Accessed 14 Oct 2014.

12. Bound J, Brown C, Mathiowetz N. Measurement error in survey data. In: Heckman JJ, Leamer E, editors. Handbook of econometrics. New York: Springer; 2002. p. 3705-843.

13. Finkelstein EAE, Trogdon JGJ, Cohen JJW, Dietz W. Annual medical spending attributable to obesity: payer-and service-specific estimates. Health Aff (Millwood). 2009;28(5):w822-31.

14. Trasande L, Liu Y, Fryer G, Weitzman M. Effects of childhood obesity on hospital care and costs, 1999-2005. Health Aff (Millwood). 2009;28(4):w751-60.

15. Thorpe KE, Florence CS, Howard DH, Joski P. The impact of obesity on rising medical spending. Health Aff (Millwood). 2004;Suppl Web W4-480-6.

16. Finkelstein EA, Fiebelkorn IC, Wang G. National medical spending attributable to overweight and obesity: how much, and who's paying? Health Aff (Millwood). 2003; Suppl Web:W3-219-26.
17. Cawley J, Meyerhoefer C. The medical care costs of obesity: an instrumental variables approach. J Health Econ. 2012;31(1):219-30.

18. Agency for Healthcare Research and Quality. Download Data Files, Documentation, and Codebooks. In: Medical Expenditure Panel Survey. U.S. Department of Health \& Human Services, Agency for Healthcare Research and Quality. 2010. Available from: http://meps.ahrq.gov/data_stats/download_data_files.jsp. Accessed 14 Oct 2014.

19. Jones A. Health econometrics. In: Culyer AJ, Newhouse JP, editors. Handbook of health economics, chap. 6, vol. 1A; 2000. pp. 265-336.

20. Manning WG, Mullahy J. Estimating log models: to transform or not to transform? J Health Econ. 2001;20(4):461-94.

21. Albu J, Pi-Sunyer FX. Obesity and Diabetes. In: Bray GA, Bouchard C, editors. Handbook of obesity: clinical applications. New York: Marcel Dekker; 2004. pp. x, 403.

22. Carroll RJ, Ruppert D, Stefanski LA. Measurement error in nonlinear models. New York: Chapman and Hall; 1995.

23. Hardin J, Schmiediche H, Carroll R. Instrumental variables, bootstrapping, and generalized linear models. Stat J. 2003;3(4):351-60.

24. Cawley J. The impact of obesity on wages. J Hum Resour. 2004;39(2):451-74.

25. Kline B, Tobias JL. The wages of BMI: Bayesian analysis of a skewed treatment-response model with nonparametric endogeneity. J Appl Econ. 2008;23(6):767-93.

26. Smith DG, Sterne JAC, Fraser A, Tynelius P, Lawlor DA, Rasmussen F. The association between BMI and mortality using offspring BMI as an indicator of own BMI: large intergenerational mortality study. BMJ. 2009;339:b5043.

27. Farooqi IS, O'Rahilly S. Genetic factors in human obesity. Obes Rev. 2007;8(Suppl 1):37-40.

28. Pietilainen KH. Genetics and epigenetics: myths or facts? In: Haslam DW, Sharma AM, Le Roux CW, editors. Controversies in obesity. London: Springer; 2014.

29. Stock J, Wright J, Yogo M. A survey of weak instruments and weak identification in generalized method of moments. J Bus Econ Stat. 2002;20(4):518-29.

30. Grilo CM, Pogue-Geile MF. The nature of environmental influences on weight and obesity: a behavior genetic analysis. Psychol Bull. 1991;110(3):520-37.

31. Wardle J, Carnell S, Haworth CM, Plomin R. Evidence for a strong genetic influence on childhood adiposity despite the force of the obesogenic environment. Am J Clin Nutr. 2008;87(2):398-404.

32. Davis K. Sample design of the 2011 medical expenditure panel survey insurance component. Methodology Report \#27. Rockville: Agency for Healthcare Research and Quality; 2013. Available from http://www.meps.ahrq.gov/mepsweb/datafiles/ publications $/ \mathrm{mr} 27 / \mathrm{mr} 27$.pdf.

33. Black D, Berger M, Scott F. Bounding parameter estimates with nonclassical measurement error. J Am Stat Assoc. 2000;95(451):739-48.

34. Frazis H, Loewenstein MA. Estimating linear regressions with mismeasured, possibly endogenous, binary explanatory variables. J Econ. 2003;117(1):151-78.

35. US Bureau of Labor Statistics. Consumer Price Indexes. BLS Handbook of Methods. Washington, DC: Bureau of Labor Statistics; 2013.

36. Krewski D, Rao JNK. Inference from stratified samples: properties of the linearization, jackknife and balanced repeated replication methods. Ann Stat. 1981;9(5):1010-9.

37. Flegal KM, Kit BK, Orpana H, Graubard BI. Association of allcause mortality with overweight and obesity using standard body 
mass index categories: a systematic review and meta-analysis. JAMA. 2013;309(1):71-82.

38. Mehta NK, Chang VW. Mortality attributable to obesity among middle-aged adults in the United States. Demography. 2009;46(4):851-72.

39. Tuomilehto J, Lindstrom J, Eriksson JG, et al. Prevention of type 2 diabetes mellitus by changes in lifestyle among subjects with impaired glucose tolerance. N Engl J Med. 2001;344(18): 1343-50.

40. Knowler WC, Barrett-Connor E, Fowler SE, et al. Reduction in the incidence of type 2 diabetes with lifestyle intervention or metformin. N Engl J Med. 2002;346(6):393-403.
41. United States Census Bureau. Population and housing unit estimates. 2014. Available from http://www.census.gov/popest/. Accessed 30 Oct 2014

42. Fontaine KR, Bartlett SJ. Access and use of medical care among obese persons. Obes Res. 2000;8(5):403-6.

43. Small D, Rosenbaum PR. War and wages: the strength of instrumental variables and their sensitivity to unobserved biases. J Am Stat Assoc. 2008;103(483):924-33.

44. Burkhauser RV, Cawley J. Beyond BMI: the value of more accurate measures of fatness and obesity in social science research. J Health Econ. 2008;27(2):519-29. 